\title{
Postoperative analgesia for pediatric craniotomy patients: a randomized controlled trial
}

\author{
Fei Xing ${ }^{1,2}$, Li Xin An ${ }^{1 *}$ (D), Fu Shan Xue1, Chun Mei Zhao² and Ya Fan Bai ${ }^{1}$
}

\begin{abstract}
Background: Pain is often observed in pediatric patients after craniotomy procedures, which could lead to some serious postoperative complications. However, the optimal formula for postoperative analgesia for pediatric neurosurgery has not been well established. This study aimed to explore the optimal options and formulas for postoperative analgesia in pediatric neurosurgery.

Methods: Three hundred and twenty patients aged 1 to 12-years old who underwent craniotomy were randomly assigned to receive 4 different regimens of patient-controlled analgesia. The formulas used were as follows: Control group included normal saline $100 \mathrm{ml}$, with a background infusion of $2 \mathrm{ml} / \mathrm{h}$, bolus $0.5 \mathrm{ml}$; Fentanyl group was used with a background infusion of $0.1-0.2 \mu \mathrm{g} / \mathrm{k} \cdot \mathrm{h}$, bolus $0.1-0.2 \mu \mathrm{g} / \mathrm{kg}$; Morphine group was used with a background

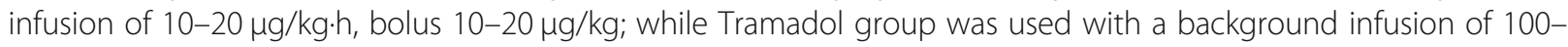
$400 \mu \mathrm{g} / \mathrm{kg} \cdot \mathrm{h}$, bolus $100-200 \mu \mathrm{g} / \mathrm{kg}$. Postoperative pain scores and analgesia-related complication were recorded respectively. Comparative analysis was performed between the four groups.

Results: In comparison of all groups with each other, lower pain scores were shown at $1 \mathrm{~h}$ and $8 \mathrm{~h}$ after surgery in Morphine group versus Tramadol, Fentanyl and Control groups $(P<0.05)$. Both Tramadol and Fentanyl groups showed lower pain scores in comparison to Control group $(P<0.05)$. Nausea and vomiting were observed more in Tramadol group in comparison to all other groups during the $48 \mathrm{~h}$ of PCIA usage after operation $(P=0.020)$. Much more rescue medicines including ibuprofen and morphine were used in Control group $(\mathrm{Cl}=0.000-0.019)$. Changes in consciousness and respiratory depression were not observed in study groups. Moderate-to-severe pain was observed in a total of 56 (17.5\%) of the study population. Multiple regression analysis for identifying risk factors for moderate-to-severe pain revealed that, younger children $(O R=1.161,1.027-1.312, P=0.017)$, occipital craniotomy (OR $=0.374,0.155-0.905, P=0.029)$, and morphine treatment $(\mathrm{OR}=0.077,0.021-0.281, P<0.001)$ are the relevant factors.
\end{abstract}

Conclusions: Compared with other analgesic projects, PCIA or NCIA analgesia with morphine appears to be the safest and most effective postoperative analgesia program for pediatric patients who underwent neurosurgical operations.

Trial registration: Chinese Clinical Trial Registry. No: ChiCTR-IOC-15007676. Prospective registration. http://www. chictr.org.cn/index.aspx.

Keywords: Pain, Postoperative, Child, Craniotomy

\footnotetext{
* Correspondence: anlixin8120@163.com

${ }^{1}$ Department of Anesthesia, Beijing Friendship Hospital, Capital Medical

University, No.95 Yongan Road, Xicheng District, Beijing 100050, China

Full list of author information is available at the end of the article
}

(c) The Author(s). 2019 Open Access This article is distributed under the terms of the Creative Commons Attribution 4.0 International License (http://creativecommons.org/licenses/by/4.0/), which permits unrestricted use, distribution, and reproduction in any medium, provided you give appropriate credit to the original author(s) and the source, provide a link to the Creative Commons license, and indicate if changes were made. The Creative Commons Public Domain Dedication waiver (http://creativecommons.org/publicdomain/zero/1.0/) applies to the data made available in this article, unless otherwise stated. 


\section{Background}

Pain after craniotomy is a frequent source of concern and controversy. Over the past decade, several studies-primarily in adult patients-have revealed that moderate-to-severe pain is common in patients after major craniotomy [1-4]. Furthermore, very few studies have assessed pain or analgesic requirements in pediatric patients following neurosurgery, primarily due to fear of opioid analgesics masking alterations in the postoperative neurological exam and delaying detection of intracranial postoperative complications [5-7]. Postoperative pain in pediatric neurosurgical patients appears to be underestimated often $[6,7]$. Inadequate pain control in children after major craniotomy may contribute to significant anxiety, hypertension, shivering, and emesis, which may in turn increase intracranial pressure and cause bleeding $[8,9]$. Therefore, although frequently overlooked, postoperative analgesia in children after craniotomy is important.

Opioids are the most frequently prescribed analgesics for moderate-severe pain. However, they may be associated with side effects such as nausea, vomiting, pruritus, respiratory depression, and neurological alterations [1012]. In particular, treatment of postoperative pain after craniotomy without affecting neurological status remains a major clinical problem. Recent studies have reported neurosurgical postoperative pain in pediatric patients can be managed with opioids without neurologic deterioration [6,7]. Nevertheless, these reports are mostly small cohort studies and reviews. So far, no prospective randomized controlled trial has been conducted on postoperative pain in pediatric neurosurgery.

Therefore, the aim of this prospective, randomized, controlled study is to assess the safety and efficacy of different postoperative pain treatment in pediatric craniotomy patients. We selected the most commonly used postoperative analgesic formulas in clinical practice in accordance with our previous research, and assumed that one of the postoperative pain treatment formulas has the best analgesic effect and no related side effect for 1-12 years old children undergoing craniotomy, so as to find an optimal formula for pediatric neurosurgery postoperative analgesia.

\section{Methods}

\section{Study design and participants}

This randomized controlled clinical trial was approved by the Institutional Review Board of Beijing Tiantan Hospital Affiliated to Capital Medical University (Beijing, China, KY2015-009-01). Written informed consent was obtained from all patients' parents. This study was conducted at a single tertiary medical center (Beijing Tiantan Hospital) and indexed in the Chinese Clinical Trial Registry (http:// www.chictr.org.cn/index.aspx, ChiCTR-IOC-15007676).
The inclusion criteria were as follows: Patients aged 112 years, with American Society of Anesthesiologists physical status grades I-III undergoing open craniotomy procedures. Eligible subjects included patients undergoing surgery for brain tumors, craniofacial reconstruction and vascular malformations. Exclusion criteria included: Mental disorders; unsuitability for extubation; and development of hematomas or severe brain edema 3 days after surgery, requiring a subsequent operation. Additionally, we excluded patients with a history of allergy to opioids or other anesthetics, and those with a history of substance abuse. Patients were enrolled in this study only after obtaining written informed consent from their parents.

\section{Anesthesia}

Standard monitoring was implemented in the operating room. All children were monitored for non-invasive blood pressure (BP), heart rate (HR) and pulse oximetry $\left(\mathrm{SpO}_{2}\right)$; as well as invasive arterial pressure (ARP), end-tidal carbon dioxide partial pressure $\left(\mathrm{P}_{\mathrm{ET}} \mathrm{CO}_{2}\right)$, and minimum alveolar concentration (MAC). Midazolam $0.025-0.075 \mathrm{mg} / \mathrm{kg}$ and methylprednisolone sodium succinate $1-2 \mathrm{mg} / \mathrm{kg}$ were given before surgery. If necessary, patients were given oral midazolam $0.5 \mathrm{mg} / \mathrm{kg}$ to reduce anxiety before venous access.

Anesthesia was induced with the following approximate doses: Propofol $(2 \mathrm{mg} / \mathrm{kg})$, cisatracurium $(0.2 \mathrm{mg} /$ $\mathrm{kg})$, and sufentanyl $(0.3 \mu \mathrm{g} / \mathrm{kg})$ or fentanyl $(3 \mu \mathrm{g} / \mathrm{kg})$. In patients aged $<5$ years or those unable to cooperate with the anesthesiologist, tracheal intubation was performed under induction with $6-8 \%$ sevoflurane inhalation before peripheral venous access. Prior to surgical incision, local infiltration with $0.5 \%$ ropivacaine was performed at the surgical site, and surgical pin sites was placed. Anesthesia was maintained with $0.5 \mathrm{MAC}$ sevoflurane at an inhalational concentration of $2-3 \%$, and an intravenous infusion with remifentanil 0.1$0.2 \mu \mathrm{g} / \mathrm{kg} / \mathrm{min}$ and propofol $3-5 \mathrm{mg} / \mathrm{kg} / \mathrm{h}$. Mean arterial blood pressure and heart rate were maintained within $20 \%$ of baseline measures. $30 \mathrm{~min}$ before the end of the operation, additional sufentanyl $5 \mu \mathrm{g}$ or fentanyl $0.5-$ $1 \mu \mathrm{g} / \mathrm{kg}$ was administered, while inhalation of sevoflurane and the infusion of remifentanil and propofol was stopped at the end of the operation. The parameters for mechanical ventilation were set to volume control with a tidal volume of $8-10 \mathrm{ml} / \mathrm{kg}$ and a respiratory rate of 14-20 times/min. Controlled mechanical ventilation maintained $\mathrm{P}_{\mathrm{ET}} \mathrm{CO}_{2}$ of $30-35 \mathrm{mmHg}$ using a $50 \%$ oxygen-air gas mixture. Additional rocuronium was administered, if needed, to maintain a train-of-four count of 2-3 intraoperatively. Whether patients received a central and arterial cannula after anesthesia induction was according to the needs of the operation. 


\section{Postoperative pain treatment protocol}

After surgery, patients aged 1-6 years received a pump for nurse-controlled intravenous analgesia (NCIA), while those aged 7-12 received one for patient-controlled intravenous analgesia (PCIA). Based on our previous cohort study of pediatric postoperative analgesia, we found that only $12 \%$ in $1-6$ years old and $58 \%$ in $7-12$ years old patients used PCIA or NCIA after craniotomy [13]. Same results were obtained in another cohort study performed by Maxwell LG ${ }^{7}$. That means that single intravenous administration after operation is a common method of postoperative analgesia in pediatric neurosurgery. So in our study we used saline in PCIA/NCIA plus rescue medicine as our control group.

The regimens of PCIA or NCIA used the following formulas: Control (group C) included normal saline 100 $\mathrm{ml}$, with a continuous background infusion of $2 \mathrm{ml} / \mathrm{h}$, bolus $0.5 \mathrm{ml}$; Fentanyl (group F) was used with a loading dose of $0.5 \mu \mathrm{g} / \mathrm{kg}$, a single bolus dose of $0.1-0.2 \mu \mathrm{g} / \mathrm{kg}$, and a background dose $0.1-0.2 \mu \mathrm{g} / \mathrm{k} \cdot \mathrm{h}$; Morphine (group M) was used with a loading dose of $50 \mu \mathrm{g} / \mathrm{kg}$, a single bolus dose of $10-20 \mu \mathrm{g} / \mathrm{kg}$, and a background dose of 10-20 $\mu \mathrm{g} / \mathrm{kg} \cdot \mathrm{h}$; while Tramadol (group T) was used with a loading dose of $500 \mu \mathrm{g} / \mathrm{kg}$, a single bolus dose of 100 $200 \mu \mathrm{g} / \mathrm{kg}$, and a background dose of $100-400 \mu \mathrm{g} / \mathrm{kg} \cdot \mathrm{h}$. The bolus locking time was $15 \mathrm{~min}$. The total volume contained in the analgesia pump was adjusted to $100 \mathrm{ml}$ with normal saline and $0.4 \mathrm{mg} / \mathrm{kg}$ of ondansetron. Patients would receive additional doses of ondansetron if they reported nausea or experienced vomiting. The type and dosed of medicines used in pump were converted to their respective milligram morphine equivalents (MME) using standardized conversion factors (1 mg of Fentanyl = $100 \mathrm{MME}, 1 \mathrm{mg}$ of tramadol = 0.1 MME) [14].

As a rescue medicine, ibuprofen suspension $(20 \mathrm{mg} / \mathrm{ml}$ ibuprofen) was oral administered in the postoperative period in doses of $0.3 \mathrm{ml} / \mathrm{kg}$ for moderate pain (defined as a pain score $\geq 4$ and $<7$ ) within 48 postoperative hours. If the POPI is severe pain (defined as a pain score $\geq 7$ ) or the first administration of ibuprofen couldn't comfort the patient within $30 \mathrm{~min}$, another rescue medicine intravenous morphine $0.02 \mathrm{mg} / \mathrm{kg}$ would be administered through peri vein. All rescue medicines were recorded.

\section{Evaluation of pain intensity}

The primary outcome of this study was postoperative pain intensity (POPI). According to the particular characteristics of each patient, we adopted different evaluation methods for POPI. Patients aged 1-6 years were evaluated by the Faces, Legs, Activity, Cry and Consolability Scale (FLACC, 0-10 scores) and the Wong-Baker Faces Scale (WBFS). For patients aged 7-12 years, both the numeric rating scale (NRS) and the Wong-Baker Faces Scale (WBFS) were used. The FLACC is a behavioral pain assessment tool that was developed to provide a simple and consistent evaluation method for these cases [15], while the WBFS is a self-reported pain assessment tool, currently considered the preferred alternative for pain assessment in children [16]. The WBFS is comprised of a series of facial images, in which the face that depicts the most pain indicates the "worst pain imaginable" and the happiest face indicates "no pain" [15]. The numeric rating scale (NRS) is a self-reported measure of pain intensity comprised of a line marked with numbers $0-10$, in which 0 is "no pain" and 10 is the "worst pain imaginable" [17]. POPI ratings were measured at $1,2,4$, $16,24,36$ and $48 \mathrm{~h}$ after surgery by the same observer. Moderate POPI was defined as a median pain score $\geq 4$ and $<7$ on the WBFS, FLACC or NRS scales. Severe pain was defined as a median pain score $\geq 7$.

\section{Randomization and blinding}

Participants were randomly assigned 1:1:1:1 among four groups. The randomization schedule was generated by an independent investigator through a computerized randomnumber sequence. A specially selected nurse was informed of the group assignments and prepared the postoperative analgesia pumps according to the patients' weights. Anesthesiologists were blinded to grouping information. Physicians responsible for postoperative follow-up were also blinded to the grouping.

\section{Data collection}

Demographic data were recorded, including age, sex, height, weight, disease information, primary diagnosis, patients' medical history, and medications. Perioperative and anesthetic management information were also collected including: operation type; preoperative anesthetic medications; induction medications; intra-operative anesthetic medications; duration of surgery and anesthesia; and number of rescue medicine administrations.

The primary outcomes included pain scores at 1, 2, 4, $16,24,36$ and $48 \mathrm{~h}$ after surgery. Secondary outcomes included the incidence of changes in consciousness, nausea, vomiting, pruritus, respiratory depression, and addition of perioperative acetaminophen. Nausea and vomiting were recorded if episodes of patient emesis were reported on nursing flow sheets, or if anti-emetic therapy was required. Respiratory depression was operationalized as a clinically significant decline in respiratory rate which required intervention, with $\mathrm{SpO}_{2}<92 \%$.

\section{Sample size and statistical analysis}

Continuous variables were described as median and interquartile range (IQR) or mean and standard deviation (SD), as appropriate. Categorical variables (sex, site of craniotomy) were presented as frequencies and percentages. The chi-square test was used for comparing proportions, and one-way analysis of variance (ANOVA) 
was used for comparing continuous variables between groups. Because the POPI of patients was ranked data, we used Kruskal-Wallis $\mathrm{H}$-test to compare the differences of POPI among all groups. If $P<0.05$, Dunnett's T3 test was used to compare the differences of POPI between any two groups.

Our previous cohort study on POPI in pediatric craniotomy patients found that the incidence of moderate POPI in children to be approximately $45 \%$. A final sample size was calculated based on the hypothesis that PCIA could reduce the incidence of moderate POPI at least $30 \%$. A sample size of 36 patients was calculated to have a significance of $5 \%$ and a power of $80 \%$, increased to 40 after considering a $10 \%$ maximal dropout rate.

Step-wise multivariate logistic regression was used to identify predictors for moderate POPI, with results presented as odds ratios (OR) and 95\% confidence intervals (CI). Statistical analysis was performed using SPSS (version 22, BEIJING, Capital Medical University). All statistical tests were two-sided, and results were considered statistically significant when $P<0.05$.

\section{Results}

\section{Baseline characteristics}

A total of 387 consecutive patients who underwent major craniotomy were screened for study participation between January 2016 and June 2018; 192 of which were in a younger group (aged 1-6 years) and 195 in an older group (aged 7-12 years). In the younger group, 12 cases refused informed consent, 18 children remained intubated for surgical reasons, and 2 children required a second operation due to postoperative hematoma. Therefore, 160 patients were ultimately included. In the older group, 11 cases refused informed consent, 21 children remained intubated for surgical reasons, and 3 children required a second operation within $48 \mathrm{~h}$ of surgery. Therefore, 160 patients (91 males and 69 females) were finally included. An explanatory flow chart is depicted in Fig. 1.

The baseline clinical characteristics in all pediatric patients are presented in Tables 1 . No significant differences were found regarding these variables among the four PCIA regimens either in the younger or older pediatric patients.

\section{Postoperative pain intensity}

Pain intensity was evaluated at 1, 2, 4, 16, 24, 36 and 48 $\mathrm{h}$ after surgery (Table 2 ). In the younger patients, over time, the pain intensity gradually decreased, and increased slightly at $24 \mathrm{~h}$ after surgery (Additional file 1 : Figure S1 and S2). The differences of WBFS/FLACC scores were significantly among all groups at $1-8 \mathrm{~h}(P<$ 0.05 ) by Kruskal-Wallis test. Through Dunnett's T3 test, lower pain scores (Both WBFS/FLACC Scores) were shown at $1 \mathrm{~h}$ and $8 \mathrm{~h}$ after surgery in Morphine Group versus Tramadol, Fentanyl and Control groups $(P<$ 0.05). Both Fentanyl and Tramadol groups showed lower pain scores in comparison to Control group $(P<0.05)$, and there is no significant difference in pain scores between the Fentanyl and Tramadol groups $(P>0.05)$ (Table 2, Additional file 1: Table S1).

In the 7-12 years older patients, a similar trend was observed (Additional file 1: Figure S3 and S4), with WBFS/NRS scores being significantly lower at $1-16 \mathrm{~h}$ in Morphine group (Table $3, P<0.05$ ). There was no significant difference between Fentanyl and Tramadol groups (Additional file 1: Table S2, $P>0.05$ ), but they were lower than Control group $(P<0.05)$.

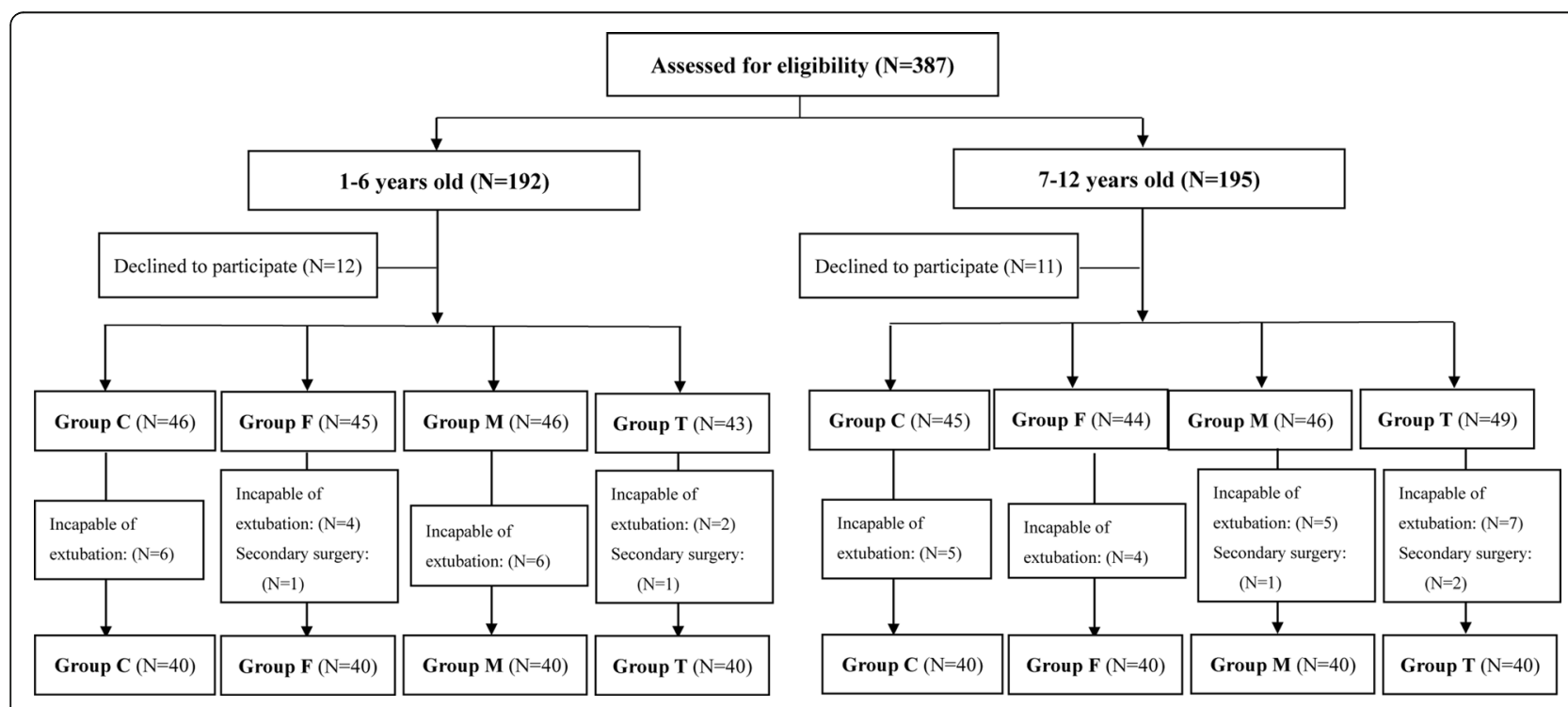

Fig. 1 Consort flow chart of participants 
Table 1 Baseline Data For all Pediatric Patients ( $1-12$ years old, $X \pm S D$ )

\begin{tabular}{|c|c|c|c|c|c|c|c|c|}
\hline & \multicolumn{4}{|c|}{ 1-6 Years Old Patients } & \multicolumn{4}{|c|}{ 7-12 Years Old Patients } \\
\hline & Group C & Group F & Group M & Group T & Group C & Group F & Group M & Group T \\
\hline Age (yr) & $4.00 \pm 1.77$ & $3.50 \pm 1.54$ & $4.05 \pm 1.45$ & $3.70 \pm 1.64$ & $8.97 \pm 2.92$ & $9.21 \pm 1.68$ & $8.51 \pm 2.69$ & $9.29 \pm 1.60$ \\
\hline Sex (male/female) & $24 / 16$ & $27 / 13$ & $24 / 16$ & $22 / 18$ & $25 / 15$ & $18 / 22$ & $24 / 16$ & $24 / 16$ \\
\hline Height (m) & $1.07 \pm 0.16$ & $1.03 \pm 0.13$ & $1.05 \pm 0.11$ & $1.06 \pm 0.14$ & $1.42 \pm 0.15$ & $1.33 \pm 0.13$ & $1.38 \pm 0.14$ & $1.40 \pm 0.13$ \\
\hline Weight (kg) & $19.8 \pm 5.4$ & $17.4 \pm 4.7$ & $18.9 \pm 6.0$ & $18.3 \pm 6.3$ & $37.7 \pm 15.5$ & $32.6 \pm 8.5$ & $34.6 \pm 10.9$ & $36.12 \pm 11.5$ \\
\hline \multicolumn{9}{|l|}{ Craniotomy site(n / \%) } \\
\hline Forehead & $24(60)$ & $19(47.5)$ & $18(45)$ & $17(42.5)$ & $22(55.0)$ & $23(57.5)$ & $21(52.5)$ & $19(47.5)$ \\
\hline Frontotemporal & $2(5)$ & $6(15)$ & $9(22.5)$ & $3(7.5)$ & $4(10.0)$ & $3(7.5)$ & $7(17.5)$ & $5(12.5)$ \\
\hline Frontoparietal & $1(2.5)$ & $1(2.5)$ & $2(5)$ & $2(5)$ & $3(7.5)$ & $2(5.0)$ & $2(5.0)$ & $3(7.5)$ \\
\hline Temporal occipital & $1(2.5)$ & $0(0)$ & $1(2.5)$ & $2(5)$ & $1(2.5)$ & $0(0.0)$ & $1(2.5)$ & $1(2.5)$ \\
\hline Occipital & $11(27.5)$ & $11(27.5)$ & $9(22.5)$ & $15(37.5)$ & $10(25)$ & $11(27.5)$ & $8(20.0)$ & $11(27.5)$ \\
\hline $\begin{array}{l}\text { Temporal-parietal } \\
\text { occipital }\end{array}$ & $1(2.5)$ & $3(7.5)$ & $1(2.5)$ & $1(2.5)$ & $0(0.0)$ & $1(2.5)$ & $1(2.5)$ & $1(2.5)$ \\
\hline VP shunt surgery $(\mathrm{Y} / \mathrm{N})$ & $5 / 35$ & $8 / 32$ & $7 / 33$ & $7 / 33$ & $7 / 33$ & $4 / 36$ & $1 / 39$ & $7 / 33$ \\
\hline $\begin{array}{l}\text { Durations of surgery } \\
\text { (min) }\end{array}$ & $217 \pm 81$ & $229 \pm 112$ & $212 \pm 67$ & $215 \pm 63$ & $299 \pm 59$ & $205 \pm 134$ & $219 \pm 49$ & $229 \pm 60$ \\
\hline $\begin{array}{l}\text { Durations of anesthesia } \\
\text { (min) }\end{array}$ & $320 \pm 98$ & $403 \pm 73$ & $310 \pm 80$ & $308 \pm 74$ & $331 \pm 77$ & $290 \pm 81$ & $311 \pm 63$ & $328 \pm 66$ \\
\hline Bleeding (ml) & $161 \pm 199$ & $109 \pm 72$ & $136 \pm 168$ & $118 \pm 93$ & $133 \pm 80$ & $113 \pm 95$ & $163 \pm 141$ & $129 \pm 80$ \\
\hline \multicolumn{9}{|c|}{ Anesthesia maintenance phase } \\
\hline Propofol (mg) & $225(155,337)$ & $190(140,367)$ & $230(160,300)$ & $220(152,340)$ & $525(292,672)$ & $350(215,555)$ & $340(200,490)$ & $280(160,480)$ \\
\hline Remifentanil (mg) & $0.63 \pm 0.34$ & $0.61 \pm 0.46$ & $0.49 \pm 0.25$ & $0.68 \pm 0.36$ & $1.07 \pm 0.59$ & $0.82 \pm 0.45$ & $0.91 \pm 0.57$ & $1.24 \pm 1.44$ \\
\hline Sevoflurane (ml) & $30 \pm 20$ & $28 \pm 22$ & $28 \pm 13$ & $24 \pm 13$ & $29 \pm 12$ & $22 \pm 12$ & $26 \pm 11$ & $27 \pm 11$ \\
\hline
\end{tabular}

No significant difference of baseline characteristics was observed

\section{Total amount of medicines used in PCIA or NCIA or for remedy}

Total amount of medicines used in the postoperative analgesia pump was calculated. After all kinds of medicines converted to their respective milligram morphine equivalents (MME) using standardized conversion factors, the average morphine equivalent amount in each day was similar between Fentanyl and Morphine groups, and in Tramadol group was a little bit higher (Table 4). As rescue medicines, the total amount and cases of ibuprofen and morphine used in Control group were much higher than that in Fentanyl, Morphine and Tramadol groups, this result was similar in both 1-6 years old patients and 7-12 years old patients.

Table 2 Postoperative Pain Scores For 1-6 Years Old Younger Pediatric Patients (median (interquartile range))

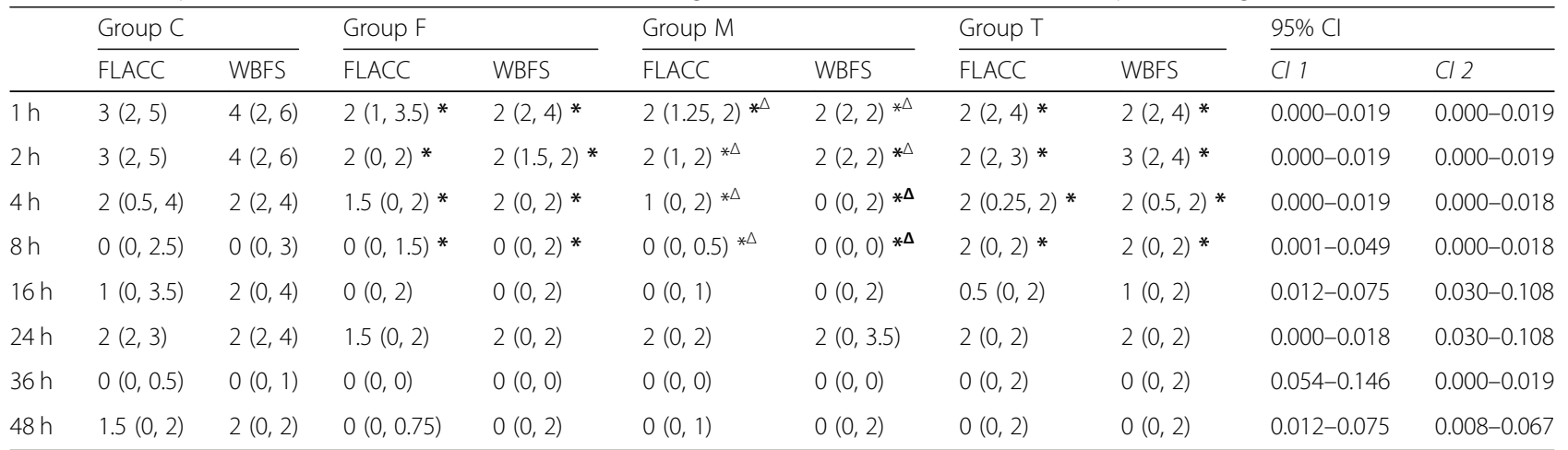

Cl 1: 95\% Confidence interval for FLACC score among four groups by Kruskal-Wallis H-test; Cl 2: $95 \%$ Confidence interval for WBFS score among four groups by Kruskal-Wallis H-test ${ }^{*} P<0.05$, the difference was significant compared with group $C$ by Dunnett's T3 test;

$\Delta P<0.05$, compared with group $F$ and $M$, the FLACC and WBFS in group M was significant lower through Dunnett's T3 test 
Table 3 Postoperative Pain Scores For 7-12 Years Old Senior Pediatric Patients (median (interquartile range))

\begin{tabular}{|c|c|c|c|c|c|c|c|c|c|c|}
\hline & \multicolumn{2}{|c|}{ Group C } & \multicolumn{2}{|l|}{ Group F } & \multicolumn{2}{|l|}{ Group M } & \multicolumn{2}{|l|}{ Group T } & \multicolumn{2}{|l|}{$95 \% \mathrm{Cl}$} \\
\hline & WBFS & NRS & WBFS & NRS & $\overline{\text { WBFS }}$ & NRS & WBFS & NRS & $\overline{C l} 1$ & $\mathrm{Cl} 2$ \\
\hline $1 \mathrm{~h}$ & $4(2,6)$ & $4(2,5)$ & $2(2,4) *$ & $2(2,3.3) *$ & $2(2,4) * *^{\Delta}$ & $2(2,3) * \Delta$ & $2(2,4) *$ & $2(2,4) *$ & $0.000-0.021$ & $0.000-0.044$ \\
\hline $2 \mathrm{~h}$ & $4(2,4)$ & $3(2,4)$ & $2(2,4) *$ & $2(2,4) *$ & $2(2,2) * \Delta$ & $2(2,3) * \Delta$ & $4(2,4) *$ & $4(2,4) *$ & $0.038-0.129$ & $0.018-0.094$ \\
\hline $4 \mathrm{~h}$ & $2(0,4)$ & $2(0,4)$ & $2(0,2.5) *$ & $2(0,3) *$ & $0(0,2) * \Delta$ & $0(0,2) *^{\Delta}$ & $2(2,4) *$ & $2(2,4) *$ & $0.000-0.021$ & $0.000-0.021$ \\
\hline $8 \mathrm{~h}$ & $2(0,2)$ & $2(0,2)$ & $0(0,2) *$ & $0(0,2) *$ & $0(0,0) * \Delta$ & $0(0,0) * \Delta$ & $2(0,2) *$ & $2(0,2) *$ & $0.000-0.021$ & $0.000-0.021$ \\
\hline $16 \mathrm{~h}$ & $2(0,2)$ & $2(0,2)$ & $0(0,2) *$ & $0(0,2) *$ & $0(0,2) * \Delta$ & $0(0,2) * \Delta$ & $2(0,2) *$ & $2(0,2) *$ & $0.001-0.055$ & $0.000-0.021$ \\
\hline $24 \mathrm{~h}$ & $2(2,4)$ & $2(2,4)$ & $2(2,2)$ & $2(1,2)$ & $2(0,2)$ & $2(0,2)$ & $2(1,2)$ & $2(1,2)$ & $0.500-0.661$ & $0.507-0.668$ \\
\hline $36 \mathrm{~h}$ & $0(0,0)$ & $0(0,1)$ & $0(0,0)$ & $0(0,0)$ & $0(0,0)$ & $0(0,0)$ & $0(0,2)$ & $0(0,1)$ & $0.485-0.648$ & $0.346-0.508$ \\
\hline $48 \mathrm{~h}$ & $2(0,2)$ & $2(0,2)$ & $0(0,2)$ & $0(0,2)$ & $0(0,2)$ & $0(0,2)$ & $0(0,2)$ & $0(0,2)$ & $0.044-0.138$ & $0.023-0.103$ \\
\hline
\end{tabular}

Cl 1: $95 \%$ Confidence interval for WBFS score among four groups by Kruskal-Wallis H-test:

Cl 2: $95 \%$ Confidence interval for NRS score among four groups by Kruskal-Wallis H-test

${ }^{*} P<0.05$, the difference was significant compared with group $C$ by Dunnett's T3 test;

$\Delta P<0.05$, compared with group $\mathrm{F}$ and $\mathrm{M}$, the WBFS and NRS in group $\mathrm{M}$ was significant lower through Dunnett's T3 test

Identical factors associated with moderate postoperative pain intensity

Moderate-to-severe pain was observed in a total of 56 $(17.5 \%)$ of the all study population. There were $26 \mathrm{pa}-$ tients in $1-6$ years old groups $(26 / 160,16.25 \%)$ and 30 patients in 7-12 years old groups (30/160, 18.75\%). Only 3 children experienced severe pain in Control group and 1 child in Tramadol group among 1-6 years old patients. And there were 5 patients in Control Group experienced severe pain among 7-12 years old patients. Single regression analysis for identifying risk factors revealed that, older age, site of craniotomy, dose of remifentanil and PCIA group were associated with moderate-to-severe POPI (Table 5). Then, multiple factor regression analysis was conducted on factors with $P>0.2$. Multiple regression analysis for identifying risk factors for moderate-to-severe pain revealed that, younger children $(\mathrm{OR}=1.161,1.027-1.312, P=0.017)$, occipital craniotomy $(\mathrm{OR}=0.374,0.155-0.905, P=0.029)$, and fentanyl treatment $(\mathrm{OR}=0.355,0.152-0.831, \mathrm{P}=0.017)$, or morphine treatment $(\mathrm{OR}=0.077,0.021-0.281, P<0.001)$ are the relevant factors (Fig. 2).

\section{Analgesia-related complications}

There was no significant difference in complications during recovery among the four groups, either in the younger or older children. In Tramadol group, 11 children suffered nausea (27.5\%) and 19 children suffered vomiting $(47.5 \%)$ within $48 \mathrm{~h}$ after surgery, which were significantly higher than that in Fentanyl, Morphine and

Table 4 Total amount of medicines used in PCIA or NCIA or for remedy (1-12 years old, $X \pm S D$ )

\begin{tabular}{|c|c|c|c|c|c|c|c|c|}
\hline & \multicolumn{4}{|c|}{ 1-6 Years Old Patients } & \multicolumn{4}{|c|}{ 7-12 Years Old Patients } \\
\hline & Group C & Group F & Group M & Group T & Group C & Group F & Group M & Group T \\
\hline \multicolumn{9}{|c|}{ Average total medicines use in PCIA or NCIA pump $(\mathrm{mcg} / \mathrm{kg} / \mathrm{d})$} \\
\hline 1st day & 0 & $5.23 \pm 1.21$ & $472 \pm 85$ & $7210 \pm 1560$ & 0 & $5.65 \pm 1.54$ & $504 \pm 105$ & $9010 \pm 2060$ \\
\hline 2nd day & 0 & $5.05 \pm 1.04$ & $495 \pm 92$ & $6780 \pm 1050$ & 0 & $5.54 \pm 0.98$ & $493 \pm 118$ & $8280 \pm 1150$ \\
\hline Morphine equivalents & 0 & $514 \pm 112$ & $486 \pm 90$ & $699 \pm 164$ & 0 & $560 \pm 112$ & $502 \pm 113$ & $864 \pm 154$ \\
\hline \multicolumn{9}{|c|}{ Total amount of Rescue medicines used in each group ( $48 \mathrm{~h}$ ) } \\
\hline Ibuprofen (P.O., mg) & 3120 & $920^{*}$ & $540^{*}$ & $1290^{*}$ & 6000 & $400^{*}$ & $840^{*}$ & $650^{*}$ \\
\hline Ibuprofen (cases / \%) & $26 / 65 \%$ & $9 / 22.5 \% *$ & $5 / 12.5 \% *$ & $12 / 30 \%^{*}$ & $27 / 67.5 \%$ & $2 / 5 \% *$ & $4 / 10 \% *$ & $3 / 7.5 \% *$ \\
\hline Comparison of Ibuprofen & \multicolumn{2}{|c|}{$X 2=27.473$} & \multicolumn{2}{|c|}{$95 \% \mathrm{Cl}=0.000-0.019$} & \multicolumn{2}{|c|}{$X 2=54.504$} & \multicolumn{2}{|c|}{$95 \% \mathrm{Cl}=0.000-0.019$} \\
\hline Morphine (I.V., mg) & 4.8 & $0.4^{*}$ & $0^{*}$ & $1.1^{*}$ & 11.1 & $0^{*}$ & $0^{*}$ & $2.2^{*}$ \\
\hline Morphine (cases / \%) & $12 / 30 \%$ & $1 / 2.5 \% *$ & $0^{*}$ & $3 / 7.5 \% *$ & $15 / 37.5 \%$ & $0^{*}$ & $0^{*}$ & $4 / 10 \% *$ \\
\hline Comparison of Morphine & \multicolumn{2}{|c|}{$X 2=20.879$} & \multicolumn{2}{|c|}{$95 \% \mathrm{Cl}=0.000-0.019$} & \multicolumn{2}{|c|}{$X 2=31.848$} & \multicolumn{2}{|c|}{$95 \% \mathrm{Cl}=0.000-0.019$} \\
\hline
\end{tabular}

Average total medicines use in PCIA or NCIA pump $(\mathrm{mcg} / \mathrm{kg} / \mathrm{d})$ :

1 st day (2nd day), Group $\mathrm{F}=$ Total Fentanyl per kg used in pump during the first postoperative day (second day); Group $\mathrm{M}=$ Total Morphine per kg used in pump during the first postoperative day (second day); Group $\mathrm{T}=$ Total Tramadol per kg used in pump during the first postoperative day (second day) Morphine equivalents: All medicines converted to their morphine equivalents, and the average total morphine per kg used in pump per day Total amount of Rescue medicines used in each group (48 h): As rescue medicines, the total amount and cases(\%) of ibuprofen or morphine used in one group; ${ }^{*} P<0.001$ compared with Group $C$ 
Table 5 Univariate Logistic Regression Analysis Of Influencing Factors Of Pain Scores For 1-12 Years Old Patients

\begin{tabular}{|c|c|c|c|c|c|}
\hline & WBFS $<4(n=264)$ & WBFS $\geq 4(n=56)$ & OR & $95 \% \mathrm{Cl}$ & $P$ \\
\hline Age (yr) & $6.25 \pm 3.16$ & $7.08 \pm 3.26$ & 1.085 & $(0.988-1.192)$ & 0.088 \\
\hline Sex (male/female) & $151 / 113$ & $37 / 19$ & 1.455 & $(0.782-2.708)$ & 0.237 \\
\hline Height (m) & $1.20 \pm 0.21$ & $1.25 \pm 0.23$ & 0.981 & $(0.875-1.100)$ & 0.741 \\
\hline Weight (kg) & $26.1 \pm 12.5$ & $28.1 \pm 11.7$ & 1.013 & $(0.990-1.036)$ & 0.275 \\
\hline \multicolumn{6}{|l|}{ Craniotomy site(n / \%) } \\
\hline Forehead & $75(28.4)$ & $25(45.3)$ & Ref & Ref & \\
\hline Frontotemporal & $93(35.2)$ & $13(22.6)^{*}$ & 0.418 & $(0.200-0.877)$ & 0.021 \\
\hline Frontoparietal & $13(4.8)$ & $6(11.3)$ & 1.400 & $(0.475-4.127)$ & 0.542 \\
\hline Temporal occipital & $5(2.0)$ & $0(0)$ & 0.000 & $(0.000-0.000)$ & 0.999 \\
\hline Occipital & $74(28.0)$ & $11(18.9)^{*}$ & 0.400 & $(0.179-0.894)$ & 0.026 \\
\hline Temporal-parietal occipital & $4(1.6)$ & $1(1.9)$ & 0.700 & $(0.075-6.565)$ & 0.755 \\
\hline $0.5 \%$ Ropivacaine for local anesthesia $(\mathrm{Y} / \mathrm{N})$ & $14 / 250$ & $3 / 53$ & 0.914 & $(0.251-3.327)$ & 0.892 \\
\hline VP shunt surgery $(\mathrm{Y} / \mathrm{N})$ & $42 / 222$ & $8 / 48$ & 1.071 & $(0.470-2.444)$ & 0.870 \\
\hline Durations of surgery (min) & $222 \pm 87$ & $205 \pm 62$ & 0.997 & $(0.992-1.001)$ & 0.174 \\
\hline Durations of anesthesia (min) & $315 \pm 80$ & $300 \pm 68$ & 0.997 & $(0.993-1.001)$ & 0.201 \\
\hline Bleeding (ml) & $132 \pm 117$ & $134 \pm 158$ & 1.000 & $(0.998-1.002)$ & 0.913 \\
\hline \multicolumn{6}{|l|}{ Anesthesia maintenance phase } \\
\hline Propofol (mg) & $315 \pm 224$ & $326 \pm 242$ & 1.000 & $(0.999-1.001)$ & 0.747 \\
\hline Remifentanil (mg) & $0.73 \pm 0.47$ & $0.84 \pm 0.57^{*}$ & 1.644 & $(1.016-2.658)$ & 0.043 \\
\hline Sevoflurane (ml) & $23.3 \pm 17.1$ & $19.3 \pm 14.9$ & 0.983 & $(0.964-1.004)$ & 0.106 \\
\hline \multicolumn{6}{|l|}{ Group (n / \%) } \\
\hline Placebo & $55(20.8)$ & $24(43.4)$ & Ref & Ref & \\
\hline Fentanyl & $71(26.8)$ & $12(20.8)^{*}$ & 0.364 & $(0.167-0.793)$ & 0.011 \\
\hline Morphine & 75 (28.4) & $4(7.5)^{*}$ & 0.083 & $(0.024-0.291)$ & $<0.001$ \\
\hline Tramadol & $63(24.0)$ & $16(28.3)$ & 0.500 & $(0.238-1.050)$ & 0.067 \\
\hline
\end{tabular}

Control groups (Additional file 1: Table S3, $P<0.05$ ). Changes in consciousness and respiratory depression were not observed in study groups $(P=0.061)$. In the younger patients, much children needed ibuprofen suspension and intravenous morphine as rescue medicine in the Tramadol and Control groups than that in the Fentanyl and Morphine groups $(P<0.05)$. In the $7-12$ years old patients, the cases of used rescue medicine in the Control group were much higher than that in Fentanyl, Morphine and Tramadol groups (Additional file 1: Table S4, $P<0.05$ ).

\section{DISSCUSION}

Although research has demonstrated $41-76 \%$ of adult patients experience moderate-severe pain within $48 \mathrm{~h}$ after craniotomy $[18,19]$, very few studies have focus specifically on the incidence and treatment of POPI in pediatric neurosurgery patients $[20,21]$. In this prospective, randomized, controlled clinical study conducted at a single academic hospital, we found POPI could be well controlled with opioids administration by NCIA or
PCIA. Compared to the opioid groups (Fentanyl and Morphine groups), the Control group needed more rescue medicine - ibuprofen suspension or morphine. In contrast, complications during recovery such as respiration depression and consciousness changes showed no significant difference among all groups. Finally, factors such as younger age, occipital site craniotomy, Fentanyl or Morphine treatment were the relevant factors.

To date, few studies have formally recommended postoperative pain treatment protocols in pediatric neurosurgery. A prospective cohort study conducted in three academic children's hospitals has previously reported POPI to be mild in children under various analgesic regimens [7]. However, this was a cohort study which only included where POPI was not accurately assessed. In contrast, Bronco [6]. found 16\% of pediatric neurosurgical patients suffered moderate-severe pain in the recovery room, and $6 \%$ patients suffered moderate-severe pain in the first and second days after surgery despite application of multimodal analgesia [6]. The main analgesic methods advocated in current studies are multimodal analgesia and 


\begin{tabular}{|c|c|c|c|c|c|}
\hline & OR & $95 \% \mathrm{CI}$ & $\mathbf{H a z}$ & zard Ration & $\begin{array}{l}P \text { Value for } \\
\text { interaction }\end{array}$ \\
\hline Age & 1.161 & $(1.027-1.312)$ & & 4 & 0.017 \\
\hline \multicolumn{6}{|l|}{ Craniotomy site } \\
\hline Forehead & ref & ref & & & \\
\hline Frontotemporal & 0.456 & $(0.195-1.065)$ & +1 & & 0.070 \\
\hline Frontoparietal & 1.552 & $(0.452-5.326)$ & $\longmapsto$ & $\longrightarrow$ & 0.485 \\
\hline Temporal occipital & 0.000 & $(0.000-0.000)$ & - & & 0.999 \\
\hline Occipital & 0.374 & $(0.155-0.905)$ & 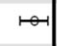 & & 0.029 \\
\hline Temporal-parietal occipital & 0.510 & $(0.041-6.393)$ & & $\square$ & 0.601 \\
\hline Durations of surgery & 1.000 & $(0.994-1.005)$ & & & 0.907 \\
\hline \multicolumn{6}{|l|}{ Anesthesia maintenance phase } \\
\hline Remifentanil & 1.175 & $(0.522-2.642)$ & $\mapsto$ & $\longrightarrow$ & 0.697 \\
\hline Sevoflurane & 0.986 & $(0.958-1.015)$ & & & 0.331 \\
\hline \multicolumn{6}{|l|}{ Group } \\
\hline Placebo & ref & ref & & & \\
\hline Fentanyl & 0.355 & $(0.152-0.831)$ & $\mapsto-1$ & & 0.017 \\
\hline Morphine & 0.077 & $(0.021-0.281)$ & $H$ & & $<0.001$ \\
\hline \multirow[t]{3}{*}{ Tramadol } & 0.438 & $(0.195-0.983)$ & $*$ & & 0.045 \\
\hline & & 2 & 0 & $i$ & \\
\hline & & & & $\overline{\text { moderate-se }}$ & ain \\
\hline
\end{tabular}

Fig. 2 OR $(95 \% \mathrm{Cl})$ for the associations between factors and moderate-severe POPI ( $\geq 4)$. A multiple factor regression analysis was conducted including all factors with $P<0.2$ in univariate logistic regression analysis results. Craniotomy site expressed different craniotomy approaches. Durations of surgery meant the length of operation. Remifentanil means the total amount of the use of remifentanil during anesthesia. The total amount of sevoflurane use is calculated based on the patients' inhaled concentration and fresh gas flow and time. A total of 14 factors were included. For multiple groups of categorical variables, we chose one of them as the reference. So, we chose forehead in craniotomy site and placebo group in groups as reference. Age, occipital craniotomy, give fentanyl PCIA or NCIA, or give morphine PCIA or NCIA, were correlated risk factors of moderate-severe pain

PCIA or NCIA analgesia [5, 7]. Maxwell et al. [7] have demonstrated that PCIA or NCIA analgesia is an effective analgesia with a low incidence of opioid-related side effects; although it should be noted that the analgesic pump settings in their study were not standardized. Chiaretti [22] found PCIA with fentanyl plus midazolam could effectively relieve postoperative pain in pediatric neurosurgery. However, their study only included patients over the age of 6 , all of whom were managed in an ICU setting. In this study, we enrolled pediatric patients in the range of 1-12 years of age. In addition, we have implemented three different methods of analgesia to compare with control group, in order to obtain the best analgesic regimen used in children.

Our study revealed that in both younger and older pediatric patients, morphine administration was the most effective regimen of PCIA or NCIA after neurosurgery. These results are consistent with those of Warren [23] who suggested continuous morphine infusions (CMI) had an analgesic effect comparable to that of acetaminophen and codeine; yet codeine phosphate alone is typically preferred as the standard treatment for pain after cranial surgery. The Fentanyl and Tramadol groups had similar analgesic effects; echoing results by Alencar [24] in neonates. Except for nausea and vomiting, no difference was observed in the incidence of side effects, and serious side effects such as respiratory depression and altered consciousness were not observed. Respiratory depression and excessive sedation are the two most feared adverse consequences of intravenous opioid use for postoperative pain in neurosurgery; as excessive sedation affects neurological status, and respiratory depression could cause negative physiological consequences such as elevated carbon dioxide levels and alterations of cerebral perfusion and intracranial pressure. In our study, these side effects were not observed. The incidence of nausea and vomiting was not significantly higher in the morphine or fentanyl groups, but was higher in the tramadol group. In a meta-analysis of postoperative PCIA in adults, Fentanyl has been ascertained to be as effective as Tramadol, but the incidence of nausea and vomiting is higher in the Tramadol group [25]. This is similar to our results in children.

Our study is a randomized controlled trial which balanced the confounding factors well. The assessment of pain in pediatric population presents a significant challenge. Children may often be unable to accurately describe the intensity of their pain. Thus, in our study, we used 2 different pain scales suitable for each age range. In order to avoid bias, research assistants who collected postoperative pain data in our study received subspecialty training in pediatric pain assessment. All 
patients were followed up by the same research assistants. We found pain scores gradually decreased with time, regardless age and treatment regimen, with a small ascent occurring at $24 \mathrm{~h}$. In addition, pain scores at 8, 16 and $36 \mathrm{~h}$ were lower than their following time point; this might be due to the fact that children were asleep at night at these points, with lower responses to pain perception. Although much rescue medicines including oral ibuprofen suspension and intravenous morphine were used in Control group compared with other groups, the POPI in Control group was still much higher than other groups, especially within the first $8 \mathrm{~h}$ after surgery. The morphine equivalents amount in Tramadol group was higher than that in Fentanly and Morphine groups, which may be owned to the over-estimated tramadol MME ( $1 \mathrm{mg}$ tramadol $=0.1 \mathrm{mcg}$ morphine) .

We also analyzed the factors affecting postoperative pain scores by multivariate logistic regression, proving the good control of confounding factors. We found age, craniotomy site and Fentanyl and Morphine treatment were predictors of POPI. Previous studies had described POPI to vary in different craniotomy sites due to the distribution of nerve endings $[5,17$, 18]. Pain scores also varied with age, this may be owned to that older children describe pain intensity with increased accuracy.

There are several limitations to our study. First, we performed local anesthesia of the surgical incision with $0.5 \%$ ropivacaine instead of scalp nerve block, a more effective auxiliary analgesia. This method may provide longer lasting analgesia in comparison to local analgesia, perhaps decreasing POPI, especially in the early postoperative period. Secondly, in our multivariate logistic regression, we found the craniotomy site was associated with postoperative pain, but a sub-group analysis was not performed as the subsamples who underwent craniotomy at different sites were relatively small. Therefore, our next step is to find more individualized analgesia regimens for patients with different craniotomy sites, in combination with scalp nerve block [26, 27].

\section{Conclusions}

Our study indicates that factors such as younger age, occipital site craniotomy, use of fentanyl or morphine are the relevant factors for moderate-to-severe pain. PCIA or NCIA with morphine could significantly decrease postoperative pain scores without increasing the incidence of nausea, vomiting, respiratory depression and excessive sedation in pediatric patients after neurosurgery. These patients may benefit from application of our postoperative analgesia protocol.

\section{Additional file}

Additional file 1: Table S1. Supplementary details for Table 2 of POPI in 1-6years old pediatric patients. The details including $95 \% \mathrm{Cl}$ and $\mathrm{H}(\mathrm{K})$ value for pain scores among four groups by Kruskal-Wallis H-test in 1-6 years old patients. Table S2. Supplementary details for Table 3 of POPI in 7-12 years old pediatric patients. The details including $95 \% \mathrm{Cl}$ and $\mathrm{H}(\mathrm{K})$ value for pain scores among four groups by Kruskal-Wallis H-test in 7-12 years old patients. Table S3. Supplementary details for Perioperative Events Experienced For 1-6 Years Old Younger Pediatric Patients. The results of perioperative events experienced for 1-6 years old patients. The cases suffered nausea and vomiting in Tramadol group were significantly higher than that in Fentanyl, Morphine and Control groups. Table S4. Supplementary details for Perioperative Events Experienced For 7-12 Years Old Senior Pediatric Patients. The results of perioperative events experienced for 7-12 years old patients. There was no different in pain intensity after the removal of intubation. But the incidence of nausea in Tramadol group were much higher than that in Fentanyl, Morphine and Control groups. Figure S1. Comparison of post-operative pain intensity of FLACC in patients aged 1-6years among the four study groups. The FLACC in 1-6years old pediatric patients, over time, the pain intensity gradually decreased, and increased slightly at $24 \mathrm{~h}$ after surgery. Figure S2. Comparison of post-operative pain intensity of WBFS in patients aged 1-6 years among the four study groups. The WBFS in 1-6years old pediatric patients, the pain score gradually decreased within $8 \mathrm{~h}$ after surgery, and increased slightly at $24 \mathrm{~h}$. Data are presented as the mean visual analog score. Figure S3. Comparison of post-operative pain intensity of NRS in patients aged 7-12 years among the four study groups. The NRS in 7-12 years old pediatric patients, over time, the pain intensity gradually decreased, and increased slightly at $24 \mathrm{~h}$ after surgery. Data are presented as the mean visual analog score. Figure S4. Comparison of post-operative pain intensity of WBFS in in patients aged 7-12 years among the four study groups. The WBFS in 7-12 years old pediatric patients, the pain score gradually decreased within $8 \mathrm{~h}$ after surgery, and increased slightly at $24 \mathrm{~h}$. Data are presented as the mean visual analog score. (DOCX $15891 \mathrm{~kb})$

\section{Abbreviations}

ARP: Invasive arterial pressure; BP: Non-invasive blood pressure; FLACC: Faces, Legs, Activity, Cry and Consolability Scale; HR: Heart rate; MME: Milligram morphine equivalents; NCA: Nurse-controlled analgesia; NRS: Numeric rating scale; PCA: Patient-controlled analgesia; $\mathrm{P}_{\mathrm{ET}} \mathrm{CO}_{2}$ : End-tidal carbon dioxide partial pressure; POPI: Postoperative acute pain intensity; $\mathrm{SpO}_{2}$ : Pulse oximetry; WBFS: Wong-Baker Faces Scale

\section{Acknowledgements}

I would like to express my sincere thanks to all doctors and nurses in the department of neurosurgery, Beijing Tiantan Hospital, Capital Medical University.

\section{Funding}

This study was supported by the Beijing Municipal Science \&Technology Commission, PR China (Grant No. Z151100004015027). The funding agent plays no role in study design, data collection, or data analyses.

\section{Availability of data and materials}

The datasets used and/or analyzed during the current study are available from the corresponding author on reasonable request.

\section{Author's contributions}

XF prepared the manuscript and implemented post-operative pain evaluation. ALX designed, interpreted the data and finally approved the version to be published. XFS assisted to prepare the draft and substantively revised it. BYF assisted to collect data and performed the statistical analysis. ZCM assisted in postoperative follow-up and the main data's acquisition. All authors had read and approved the final submitted version. All authors have agreed both to be personally accountable for their own contributions and to ensure that questions related to the accuracy or integrity of any part of the work. 


\section{Ethics approval and consent to participate}

The study protocol was approved by the IRB of Beijing Tiantan Hospital Affiliated to Capital Medical University. Approval date: May 6, 2015. Approval code: KY2015-009-01. Because all the patients included in this study were children under 12 years old with brain disorders. Their understanding and behavioral ability were limited. So the informed consent of this study was signed by the parents of the children with the approval of ethics committee. We obtained the written consent from the parents of all the participants.

\section{Consent for publication}

Not Applicable.

\section{Competing interests}

The authors declare that they have no competing interests.

\section{Publisher's Note}

Springer Nature remains neutral with regard to jurisdictional claims in published maps and institutional affiliations.

\section{Author details}

'Department of Anesthesia, Beijing Friendship Hospital, Capital Medical University, No.95 Yongan Road, Xicheng District, Beijing 100050, China. 2Department of Anesthesia, Beijing Tiantan Hospital, Capital Medical University, Beijing, China.

Received: 20 December 2018 Accepted: 31 March 2019 Published online: 11 April 2019

\section{References}

1. Tsaousi GG, Logan SW, Bilotta F. Postoperative pain control following craniotomy: a systematic review of recent clinical literature. Pain Pract. 2017; 17:968-81.

2. Suksompong S, Chaikittisilpa N, Rutchadawong T, Chankaew E, von Bormann B. Pain after major craniotomy in a university hospital: a prospective cohort study. J Med Assoc Thail. 2016;99:539-48.

3. Dilmen OK, Akcil EF, Tunali Y, Karabulut ES, Bahar M, Altindas F, et al. Postoperative analgesia for supratentorial craniotomy. Clin Neurol Neurosurg. 2016;146:90-5.

4. Peng $Y$, Zhang W, Kass IS, Han R. Lidocaine reduces acute postoperative pain after Supratentorial tumor surgery in the PACU: a secondary finding from a randomized, controlled trial. J Neurosurg Anesthesiol. 2016;28:309-15.

5. Teo JH, Palmer GM, Davidson AJ. Post-craniotomy pain in a paediatric population. Anaesth Intensive Care. 2011;39:89-94.

6. Bronco A, Pietrini $D$, Lamperti M, Somaini M, Tosi F, del Lungo LM, et al. Incidence of pain after craniotomy in children. Pediatr Anesth. 2014;24:781-7.

7. Maxwell LG, Buckley GM, Kudchadkar SR, Ely E, Stebbins EL, Dube C, et al. Pain management following major intracranial surgery in pediatric patients: a prospective cohort study in three academic children's hospitals. Pediatr Anesth. 2014:24:1132-40.

8. An LX, Chen X, Ren XJ, Wu HF. Electro-acupuncture decreases postoperative pain and improves recovery in patients undergoing a supratentorial craniotomy. Am J Chin Med. 2014;42:1099-109.

9. Hansen MS, Brennum J, Moltke FB, Dahl JB. Pain treatment after craniotomy: where is the (procedure-specific) evidence? A qualitative systematic review. Eur J Anaesthesiol. 2011;28:821-9.

10. Morad A, Winters B, Stevens R, White E, Weingart J, Yaster M, et al. The efficacy of intravenous patient-controlled analgesia after intracranial surgery of the posterior fossa: a prospective, randomized controlled trial. Anesth Analg. 2012;114:416-23.

11. Gottschalk A, Yaster M. The perioperative management of pain from intracranial surgery. Neurocrit Care. 2009;10:387-402.

12. Bauer DF, Waters AM, Tubbs RS, Rozzelle CJ, Wellons JC 3rd, Blount JP, et al. Safety and utility of scheduled nonnarcotic analgesic medications in children undergoing craniotomy for brain tumor. Neurosurgery. 2010;67: 353-5 discussion 355-356.

13. Ye H, Xie S, Li J, An LX. The observation of craniotomy postoperative pain in preschoolers (Chinese). Int J Anesth Resus. 2015;36(70):605-9.

14. Tan WH, Feaman S, Milam L, Garber V, McAllister J, Blatnik JA, et al. Postoperative opioid prescribing practices and the impact of the hydrocodone schedule change. Surgery. 2018;164:879-86.
15. Malviya S, Voepel-Lewis T, Burke C, Merkel S, Tait AR. The revised FLACC observational pain tool: improved reliability and validity for pain assessment in children with cognitive impairment. Peadiatr Anesth. 2006;16:258-65.

16. Garra G, Singer AJ, Taira BR, Chohan J, Cardoz H, Chisena E, et al. Validation of the Wong-baker FACES pain rating scale in pediatric emergency department patients. Acad Emerg Med. 2010;17:50-4.

17. Abu-Saad H. Assessing children's responses to pain. Pain. 1984;19:163-71.

18. Rocha-Filho PA. Post-craniotomy headache: a clinical view with a focus on the persistent form. Headache. 2015;55:733-8.

19. Haldar R, Kaushal A, Gupta D, Srivastava S, Singh PK. Pain following craniotomy: reassessment of the available options. Biomed Res Int. 2015;2015:509164.

20. Nelson KL, Yaster M, Kost-Byerly S, Monitto CL. A national survey of American pediatric anesthesiologists: patient- controlled analgesia and other intravenous opioid therapies in pediatric acute pain management. Anesth Analg. 2010;110:754-60.

21. Hummel P, Lawlor-Klean P, Weiss MG. Validity and reliability of the N-PASS assessment tool with acute pain. J Perinatol. 2010;30:474-8.

22. Chiaretti A, Viola L, Pietrini D, Piastra M, Savioli A, Tortorolo L, et al. Preemptive analgesia with tramadol and fentanyl in pediatric neurosurgery. Childs Nerv Syst. 2000;16:93-9 discussion 100.

23. Warren DT, Bowen-Roberts T, Ou C, Purdy R, Steinbok P. Safety and efficacy of continuous morphine infusions following pediatric cranial surgery in a surgical ward setting. Childs Nerv Syst. 2010;26:1535-41.

24. Alencar AJ, Sanudo A, Sampaio VM, Góis RP, Benevides FA, Guinsburg R. Efficacy of tramadol versus fentanyl for postoperative analgesia in neonates. Arch Dis Fetal Neonatal Ed. 2012;97:F24-9.

25. Murphy JD, Yan D, Hanna MN, Bravos ED, Isaac GR, Eng CA, et al. Comparison of the postoperative analgesic efficacy of intravenous patientcontrolled analgesia with tramadol to intravenous patient-controlled analgesia with opioids. J Opioid Manag. 2010;6:141-7.

26. Guilfoyle MR, Helmy A, Duane D, Hutchinson PJ. Regional scalp block for postcraniotomy analgesia: a systematic review and meta-analysis. Anesth Analg. 2013;116:1093-102.

27. Jayaram K, Srilata M, Kulkarni D, Ramachandran G. Regional anesthesia to scalp for craniotomy: innovation with innervation. J Neurosurg Anesthesiol. 2016;28:32-7
Ready to submit your research? Choose BMC and benefit from:

- fast, convenient online submission

- thorough peer review by experienced researchers in your field

- rapid publication on acceptance

- support for research data, including large and complex data types

- gold Open Access which fosters wider collaboration and increased citations

- maximum visibility for your research: over $100 \mathrm{M}$ website views per year

At $\mathrm{BMC}$, research is always in progress.

Learn more biomedcentral.com/submissions 